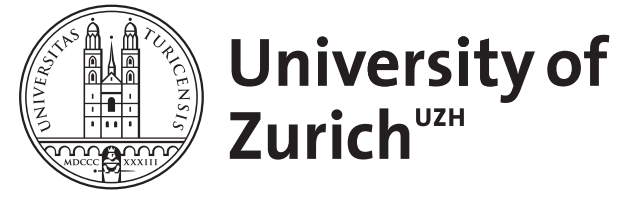

\title{
Color and Subjectivity in Film
}

Flückiger, Barbara

DOI: https://doi.org/10.4324/9781315643625

Posted at the Zurich Open Repository and Archive, University of Zurich

ZORA URL: https://doi.org/10.5167/uzh-126903

Book Section

Accepted Version

Originally published at:

Flückiger, Barbara (2017). Color and Subjectivity in Film. In: Reinerth, Maike Sarah; Thon, Jan-Noël. Subjectivity across Media : Interdisciplinary and Transmedial Perspectives. London: Routledge, 145-161. DOI: https://doi.org/10.4324/9781315643625 


\title{
Color and Subjectivity in Film
}

\author{
Barbara Flueckiger
}

When contemporary spectators watch movies, they usually do not pay attention to colors, unless the color scheme becomes very ostentatious. However, in the early days of cinema, color was one of the main attractions of the new medium, and thus an end in itself. Beautifully handcolored or stencil-colored scenes were presented as visual attractions (see Yumibe 2012). When the mimetic colors were introduced to capture profilmic colors by an immanent process- be it chemical or physical or by a combination of both - the amazement was even more pronounced. These so-called "natural" colors generated a vivid discourse in fan magazines as well as in the trade press (see Hanssen 2006; Layton et al. 2015). ${ }^{1}$

One of the recurring topics of this discourse centered on the notion of reality, whether or not color films were more real and more immediate or whether-on the contrary-colors distracted the audience. This discourse is torn between two poles: On the one hand, realism called for transparent representation of the outside world as proposed by the notion of the indexical developed, for example, by André Bazin (1975) and on the other hand the concept of verisimilitude often referred to a basic, ideologically charged norm of Hollywood's continuity system (see Bordwell, Staiger, and Thompson 1985). Our collective memory profoundly associates the exploitation or critiques of film color's notorious shift to artificiality and stylization with Technicolor's spectacular display of saturated hues.

Most of the early film color processes like tinting and toning ${ }^{2}$ primarily served the purpose of structuring the narrative, indicating locations and time, or marking narrative highlights. Starting in the first decade of the $20^{\text {th }}$ century the new mimetic processes were 
displaying constant changes in hues, color schemes and patches of colors, often referred to as “color bombardment" causing "eye strain." In a broader context, the color discourse was embedded in a heated debate about the use of colors in art, interior design, fashion, and other strands of consumer culture. Famously, David Batchelor proposed the term "chromophobia" $(2006,64)$ for Western culture's reluctance towards color. According to Batchelor, color was perceived as "the Other," associated with the vulgar, the female, the oriental, or the superficial. Batchelor's statement, however, is contested by an intense preoccupation with color by artistic movements in modernity, such as constructivism, fauvism, or the Bauhaus. Connected to these general occupations with color in art and design in the early $20^{\text {th }}$ century, the development and application of film colors were not only determined by severe technical obstacles but also influenced by cultural norms of taste and by a broader context of color uses.

When we investigate the different notions of subjectivity and color in narrative films that are the topic of this chapter, we must constantly remember these surrounding discourses. The perception of color is highly influenced by its context, be it the consumption of other media or the uses of color in other cultural spaces. Acculturation together with physiological and psychological/psycho-physical processes shape spectators' reactions to colors and, accordingly, the narrative uses of colors at a given moment in film history. Yet in many cases this web of influences goes widely unnoticed. First and foremost, colors address the senses directly. As a result, colors trigger unmediated bodily and sensorial responses of spectators. Therefore, colors are particularly suitable to express inner states, moods, and emotions.

In the course of film history, various strategies emerged to apply colors for the attunement of spectators to a character's mood and thus to his or her subjective mental state, which is at the center of the present chapter. Affective layers of colors' immediate connection to 
spectators' reactions are often combined with narrative or conventional means to express the characters' feelings and deepen the alignment of viewers with the characters. Dreams, memories, and imaginations are displayed by deviating color schemes, shifts in hue, or saturation. Differently colored segments mark narrative strands in complex, multi-faceted, or nested networks from the early days of film production with their tinted, toned, hand-colored or stencilcolored films. Lighting schemes greatly affect color appearance and can create an affectively charged ambiance.

\section{Direct Affect}

A recurring topic in early modernity, especially with regard to the use of color, was the search for an "innocent eye," that is, for an immediate perception of color devoid of cultural references, signification or symbolic layers of meaning (see Gage 1993; Riley 1995). Such a use of color corresponds to Peirce's firstness: “An instance of that kind of consciousness which involves no analysis, comparison or any process whatsoever, nor consists in whole or in part of any act by which one stretch of consciousness is distinguished from another, which has its own positive quality which consists in nothing else, and which is of itself all that it is, however it may have been brought about" (Peirce 1932, §6, 306).

It is not surprising, then, that Peirce referred to the color red to explain his concept. Colors are a prime example of qualia: an irreducible sensation that is completely subjective and internal. ${ }^{3}$ For instance, perceived redness is purely an internal state of perception, that is accessible neither to measurement nor to intersubjective comparison, despite having a material basis associated to the electromagnetic waves that generate the sensation in the human visual system (see Hurlbert 2013). 
As briefly mentioned earlier, such an innocent eye is an idealistic concept. Every perception is framed by a web of personal experience and cultural norms, informing the purely physiologic sensation, and at the same time by the viewing situation, the environment, neighboring colors. Again and again, Bauhaus theoretician Josef Albers (1970) elaborated the fundamentally nonlinear, relational character of color. In a short treatise on historical shifts in the perception of green, Bertolt Hering (2007) tracks the changing conceptions of greenness in the past two hundred years since the introduction of Philipp Otto Runge's first three-dimensional color order system, the Farbenkugel (color sphere) (see Runge 1810).

Despite the justified critical stances towards unmediated subjectivity in color perception, colors' immediate appeal to the senses remains unchallenged. Just think of entering a room painted in a particular color such as pink, dark blue, or a subdued mocha brown, a color that has become particularly fashionable in interior design during recent years. Even in your imagination, you are likely to experience an affective response. In his textbook Moving Viewers, Carl Plantinga proposed the term "direct affect" to describe such immediate affective reactions that are neither consciously processed nor caused by narrative information $(2009,117-120)$.

One of the most severe methodological obstacles in analyzing direct affects in film stems from the fact that such responses are a priori hidden from observers. There are numerous empirical investigations of feelings associated with specific hues (see, e.g., Heller 2004). However, given the complex nature of these sensations, the results of these studies vary greatly with regard to method, purpose, and environment. To escape this limitation, film scholars qualitatively investigating direct affect caused by color must rely on introspection and close analysis of the films under investigation. 
From a historiographical perspective, some general principles in addressing direct affective responses become apparent when we investigate large groups of films distributed either in certain periods, certain cultures, or in more extended frameworks. ${ }^{4}$ For instance, hyperchromaticity - the use of very saturated and bold colors, often in unusual juxtapositions - is traditionally applied to either generic framings such as dance and musical numbers, horror films, fairy tales, fantasy films, and melodramas or to emotionally charged scenes, when conflicts erupt or protagonists are scared to death. As Richard Dyer has elaborated in his essay "Entertainment and Utopia" (2002), the non-representational mode of such highlights that can occur in even the most mainstream film shares ground with artistic autonomy as commonly found in expressionist and experimental films. In these scenes, we can observe what Hermann Kappelhoff (2004) termed Ausdrucksbewegung (expressive movement), an emotionally charged connection between space and time that is intrinsically targeted at the evocation of direct affect. Characters, objects, and lights establish patterns of pure colors, thereby addressing the unmediated sensory response of the viewer/listener, often as a combination of sound/music and color similar to the abstract animations by Oskar Fischinger, Walter Ruttmann, Len Lye, or various dance numbers in musicals such as The Red Shoes (Michael Powell and Emeric Pressburger, 1948) or An American in Paris (Vincente Minelli, 1951).

\section{Ambiance and Mood}

In his seminal study The Photoplay, Hugo Münsterberg proposed as early as 1916 that films can have the capacity to subjectively transform landscapes and interiors in accordance with a protagonist's inner state. 
The feeling of the soul emanates into the surroundings and the impression which we get of our neighbor's emotional attitude may be derived from this external frame of the personality as much as from the gestures and the face.... But just this additional expression of the feeling through the medium of the surrounding scene, through background and setting, through lines and forms and movements, is very much more at the disposal of the photoartist. He alone can change the background and all the surroundings of the acting person from instant to instant. He is not bound to one setting, he has no technical difficulty in altering the whole scene with every smile and every frown. (Münsterberg 1916, 119)

This capacity has been more fully explored by developments in film aesthetics in the century since Münsterberg's study, especially in genres that address first and foremost emotional reactions in audiences, like melodramas, horror films, and epic dramas. For instance, Lawrence of Arabia (David Lean, 1962) makes extensive use of a changing environment to express the protagonist's journey and ultimately his psychological decay.

Such an externalization of feelings into the outside world is one of the key functions of film colors. Film color makes use of direct affect, introduced in the previous paragraph, by connecting the feeling of the characters to the spectators' perception. Like sound, color can be a subliminal aesthetic feature with a high potential to influence people's affective states (see Flueckiger 2001 on sound).

To discuss this topic further, a clear distinction should be drawn between affect and emotion and the use of these two terms defined for the argument to be presented. While the two concepts certainly overlap, psychological approaches to film studies tend to distinguish them quite clearly (see Plantinga 2009, 57). From this perspective, emotions are understood to rely on 
cognitive judgments of situations or objects; they are top-down processes that make use of knowledge based on previous experience or general knowledge in a given culture. An example is the fear of snakes that occurs only when an individual is aware of the dangerous potential of snakes. In film reception, such cognitive information can be provided by narrative strategies whereby a dangerous object that is not known in the real world is introduced, such as a laser sword. Affects, on the other hand, are immediate, instinctive reactions. They are generally devoid of cognitive judgments, stimulus-induced, bottom-up sensations connected to visceral bodily reactions. While Hans J. Wulff suggests that affects are always connected to objects (see Wulff 2006, 17), I would argue that they include reactions to "fuzzy objects" as well, such as an ambiance, which is caused by objects themselves only in part, but more generally associated with a certain ensemble of stimuli from an environment. In contrast to emotions, which can arise within an individual without external triggers, affects are always related to the outside worldthey occur, in other words, between subject and object.

Within the framework of these distinctions, the ambiance of places and the moods of individuals constitute a special case. The German term Stimmung connects the two concepts. Stimmung can occur both in environments and in individuals. Moreover, Stimmung in an environment—ambiance—-tends to inform an individual's Stimmung — mood—by their sensory qualities, in everyday life and in aesthetic experience.

This connection between atmospheric elements of representation with a specific mood in the concept of Stimmung was a core concept in the fin-de-siècle aesthetic and art theories of Alois Riegl and Hugo von Hofmansthal (see Arburg 2010). It was understood as a specific form to experience the world in an affectively laden status between the world's objective properties and its subjective perception, leading to an intimate attunement between subject and object. 
Colors are instrumental for this configuration. As Isaac Newton observed in Opticks, "indeed rays, properly expressed, are not coloured" (1704, VII); colors are pure sensations in the human visual system. By their intrinsic qualities they are an atmospheric element, excited by the object world, but not fully part of it. Colors in cinematic representations thus establish a general tonality, by a film's color scheme, often referred to as its palette, by specific color harmonies or chords of color (see Brinckmann 2014).

In fiction films, these color schemes are often connected to the art design of the décor, to costumes and objects. During the Technicolor era in classical Hollywood, the Technicolor company's color consultants surveyed the whole color design of each film according to the rules formulated in Natalie Kalmus's famous paper "Color Consciousness" (1935), published at the time when she was the head of the color advisory service. One dominant rule stated a hierarchy between the female protagonist, who should always be at the center of attention, supporting characters, and the environment which should be kept in unobtrusive, desaturated, and "natural" colors (see Brinckmann 2014, 33-36; Higgins 2007; Neupert 1990; Street 2009).

Even within this dogma, however, there were significant deviations from this rule, namely the inversion of figure and ground in emotionally charged scenes or the application of colored light to express inner states. Several of the most iconic shots in Gone with the Wind (Victor Fleming, 1939) show by expressive contrasts the characters as silhouettes in front of deeply saturated backgrounds: father and daughter with the tree in front of the family's manor; Tara in the sunset; Scarlet and Rhett kissing in front of the burning skies of Atlanta. Some of the most intense dialogue scenes are also staged using backlight in front of large window frames (see Higgins 2007). In fact, strategies to convey inner states by either openly or subliminally adjusting the colors of the set design are so numerous that it is impossible to elaborate this topic 
within the present chapter (however, see the bibliography on the "Timeline of Historical Film Colors" for further discussion).

Michelangelo Antonioni's Il deserto rosso (1964) is probably the most famous example of an encompassing strategy to project inner states into the environment, not just into architectural spaces, but also exteriors in nature. In a close examination of a statement by Friedrich Wilhelm Hegel, Antonioni decided to transcend the traditional boundaries by altering nature through colors. Hegel stated that, in general, landscape does not fit a state of mind as does a room or architecture. Hence, situations located in exteriors do not reflect inner states, but nature itself is receiving affirmation as a sheer environment (see Meder 1994, 75).

Rudolf Arnheim (as quoted in Fell 2000, 12) took a critical stance towards Antonioni's high level of stylization with its ostentatious use of color. By comparing the film to Robert Wiene's Das Cabinet des Dr. Caligari (1920), Arnheim identified the basic problem as a clash between flesh-and-blood acting and its artificial environment. Whether or not Antonioni's intention to convey inner states through colors in the environment reaches the audience's reception is contestable. In the context of European art cinema's new waves in the 1950s and 1960s, and in particular the use of color in Jean-Luc Godard's oeuvre with its permutational formalism, Il deserto rosso still adheres to a certain degree of verisimilitude, albeit with a high level of aesthetic sophistication and ambiguous meaning.

Philipp Otto Runge's (1840) concepts of surface colors (Körperfarben) and luminous colors (Lichtfarben) allow for the comparison of colored objects and their appearance in colored lights by filters or gels, by tinting, toning, or in color grading during postproduction. From the early days of color cinematography colored lights were applied to infuse an environment with an expressive ambiance, a technique called mood lighting (see Keating 2010). The first three-strip 
Technicolor film La Cucaracha (Lloyd Corrigan, 1934) applied mood lighting in several scenes to represent emotional changes in characters in accordance with the unfolding story. ${ }^{5}$ While $L a$ Cucaracha was still adhering to narrative functions as suggested by Kalmus, this subordination to story soon gave way to more complex and ambiguous applications of mood lighting, often at the threshold of perception and most likely beyond cognitive evaluation by spectators. In the melodrama Leave Her to Heaven (John M. Stahl, 1945), in a private moment of introspection, the male protagonist is depicted in twilight between the cool blue of the night and the yellow rays of tungsten bulbs. Under careful scrutiny, we understand that the scene is both beautiful and subtly troubling. The mixed illumination in conjunction with a noirish lighting pattern-cookie lighting — creates a highly ambivalent atmosphere, foreshadowing the destructive marriage with the heroine, a fascinatingly mean, intelligent, and beautiful femme fatale who, like a spider, draws her husband ever deeper into her web. Even if the subtle narrative hint is hardly recognized by audiences, this ambiance is persistent throughout the film, evoking an unsettling tension between beauty and horror.

Mood lighting has evolved over time into much bolder applications. From traditional forms in the 1930s and 1940s Technicolor films to more recent abstractions in the works of Godard and Fassbinder or in the giallo tradition of the 1970s, in the works of cinematographers such as Sławomir Idziak and of Asian filmmakers Wong Kar-wai and Zhang Yimou, colored lights play a significant role in establishing an emphasized level of stylization, a layer of colors that alienates and attracts the viewers simultaneously. In Douglas Sirk's melodramas Written on the Wind (1956) and All That Heaven Allows (1955), mood lighting acts as an expressive means to undermine the seemingly dominant bourgeois system to project the protagonist's oppressed feelings into the outside world, as Thomas Elsaesser (1972) notes. While Elsaesser mentions 
color as one of the most important instrument to subvert the narrative surface of these "tales of sound and fury" (Elsaesser 1972), he neither discusses the use of color in more detail, nor does he compare the Sirkian style to contemporary Technicolor aesthetics of the 1940s and 1950s. ${ }^{6}$

In recent years, cinematographer Sławomir Idziak has become famous for his daring use of colored lights and color filters, which fragment space and time into patches of autonomous colors, often creating a heightened, dreamlike ambiance. In an interview with Margarete Wach (2007), Idziak contests Vittorio Storaro’s symbolic use of colors (for instance green for "wisdom"), instead opting for a dynamic work with pure colors, freeing colors from their narrative constraints and applying them as affective values. Often starting with one color and extending it to a color scheme of adjacent or complementary color, the cinematographer established a unique aesthetic system for each film while at the same time staying true to his signature style. In Ridley Scott's Black Hawk Down (Ridley Scott, 2001) he uses the four primary hues $^{7}$ of yellow, red, green, and blue to dissolve the space into mono-, bi-, or trichrome compositions, in alignment with the protagonist's feeling of alienation and loss in their traumatic experience of war. Such applications of mood lighting greatly reduce the spatial legibility by blurring the objects' boundaries, thereby adding to the disorientation of both the characters and the viewers: "Colour forms both the architecture of an image that can be readily deciphered and its dissolution as it is complicit and disruptive of the organisation of on-screen space" (Watkins 2013, n.pag.).

In Idziak's camera work for Michael Winterbottom's film I Want You (1998), the double effect of colored lights to dissociate and to connect characters and viewers almost simultaneously becomes even more pronounced. In contrast to Black Hawk Down, I Want You allows us to observe a challenging interplay between saturated object colors and luminous colors, often 
establishing stark complementary contrasts between red and green. Moreover, graduated filters alter the color of the sky to sepia tones to evoke an indeterminate ambiance of nostalgia. Similar to Idziak's dynamic work with colors in the affective range, Christopher Doyle has largely resisted adhering to any symbolic meaning in his cinematography for Chinese filmmakers Wong Kar-wai and Zhang Yimou. An interesting point in case is Ying xiong (Zhang Yimou, 2002), internationally released as Hero, a film that applies multiple focalizations ${ }^{8}$ to narrate the story in three different versions, each of them coded in a specific color range-white, blue, and red, with a green interlude and a primary narrative in black.

We chose white to suggest the truer sequence, and we chose red to suggest that passion has a different truth. Like the West from Aristotle until Newton, Chinese conceptual systems associate color with elements, objects, parts of the body and sounds. In the Chinese tradition, green is wood, anger and the eyes. Red is fire, the veins and joy. Yellow is earth and desire. White is metal, skin, hair and sorrow. Our basic color, black, is water and fear, not the negation of color some would assume. I guess someone deserves a PhD if he applies all of those concepts to Hero. As far as I'm concerned, these colors are nothing more or less than what they are. (Doyle 2003, n.pag.)

Except for the red, which is ostentatiously associated with Western concepts of passion and "Chineseness"- to transfer Roland Barthes' concept of italianità to the Chinese realm—the filmmakers combine narrative functions with affectively laden moods that spread out to the large segments of each version, rather than adhering to Chinese symbolism.

Textures and Touch 
Colors' physical properties are intimately connected to their material basis, the material properties of the object, the small-scale variations of their surface, the dyes or pigments in connection with their binders. Shiny, glossy, matte, textured, coarse, dry, or humid and wet, smooth, or translucent and transparent: Every surface creates its individual color appearancejust compare wool to silk to cotton for an immediate impression. Color appearance is highly dependent on the reflective properties of objects, their density, their absorption and transmission. Color appearance is further specified by an object's illumination, the illuminant's color temperature, direction, diffusion, and — with regard to colors in film — the condition of the film at the moment an image is captured or the viewing condition, alongside the various influences of the film stock, its processing and color grading. In other words, color appearance is a result of the interaction between surface colors and the spectral properties of luminous colors in certain viewing conditions.

Beyond object classification and identification, color vision also clearly enhances the perception of material qualities - roughness, moisture content, luster — which in turn enables the recognition of material types themselves .... Katz (1935) was particularly concerned with the importance of color in capturing what he called the "micro-structure" of objects; "it is important not merely to perceive what the object is, but to understand what the object is made from." Shape is also not an entirely reliable or complete cue, because its retinal image varies with viewing geometry, and in many scenes objects are partially occluded. Under these conditions, the surface properties of color and texture are more robust: surface color and texture do not vary with viewpoint in the retinal image, and may be diagnostic even in a small patch of unoccluded surface. (Hurlbert 2013, 380) 
As a result, color distribution across an image conveys a myriad of material and surface properties that address - through the visual system—our haptic perception, especially touch, via intermodal association (see Bahrick and Hollich 2006). Haptic perception is one of the most immediate human sensations. Small children explore the world by touching objects, taking them into their mouthes and smashing them onto the floor or against other objects. As a result of lifelong exchange with the world by touching it, haptic properties of a film's depicted diegesis, its objects, its characters, and their costumes are highly influential in creating a bodily experience while watching a movie. Sound is likewise crucial in adding three dimensionality and tactile impressions to cinematic representations (see Flueckiger 2001). Again, the haptic dimension is equally apt to provide shared sensations between characters and audiences, as discussed in the previous section with regard to ambiance and mood. Therefore tactility is a means to align the viewers with selected characters' subjective experience of their environment.

In her phenomenological study Address of the Eye, Vivian Sobchack introduced the term "film's body" to denote an embodied perception provided by a film that affects the spectator's bodily reactions to the film (see Sobchack 1992, 164-258; with reference to color see Watkins 2013). At this intersection, touch plays a key role in connection to visceral, kinesthetic, and gustatory sensations, equally affecting the viewers' bodies. Jennifer M. Barker (2009) has analyzed at great length the role of touch for cinematic experience: "To show that it is a "style of being' shared by both film and viewer, and that particular structures of human touch correspond to particular structures of the cinematic experience. In other words, the forms of tactility that filmgoers experience at the movies are shared — in complex, not always comfortable ways - by both spectator and film. Exploring cinema's tactility thus opens up the possibility of cinema as an intimate experience and of our relationship with cinema as a close connection, rather than as a 
distant experience of observation, which the notion of cinema as a purely visual medium presumes" (2009, 2, original emphases). In a chapter entitled "Skin" (23-68), Barker explores phenomenological questions regarding both the "film's skin"—its very materiality—and the skin of the spectator. While the film's skin fundamentally informs colors' appearance on the screen, this topic is not at the center of this chapter. More important for our focus on color and subjectivity are the three topics of "Eroticism," "Pleasure," and "Horror." Each of the three topics covers an essential area of application. This chapter, however, will only partly follow Barker's observations. It will go on to establish an approach that is located between a stylistic analysis of the representation of surfaces and textures and their connection to subjective states of the characters - a concept that can be attributed to the latent subjective transformation established in the previous two sections.

In Antonioni's Il deserto rosso, touch is another important dimension in the director's use of colors. Throughout the film, there is a subtle dichotomy between man-made surfaces, covered in thick, shiny, and saturated paints, and the subdued matte and textured colors of the outside landscape, a natural environment greatly damaged by industrial exploitation. Dark marine blue paint in the female protagonist's home, applied to handrails and grids, creates a distancing cold effect that underscores the heroine's painful feelings of isolation. This effect is even more pronounced in the gathering at a hut, where the wooden structure is submerged in glossy red varnish. While the red indicates a sexually charged atmosphere, very much in tune with conventional color symbolism, the opposition between the organic material basis, the wood, and the artificial, highly synthetic coating echoes the underlying conflict between Giuliana's seeming neuroticism and the superficial shallowness of the society surrounding her. The mise en abyme of the bedtime story—recounting a girl's day at the beach in Sardinia—reflects on this tactile 
dimension by completely inverting it. It depicts the girl swimming gaily in the azure glistening Mediterranean Sea, in bright sunshine, drops of water glimmering on her tanned skin. The greyrose, rough texture of the granite rocks enhances the soft tactility of the water's soothing transparent and fluid quality. Affective qualities thus connect the protagonist—located in a tension between the muted industrial environment often immersed in fog and the dominating object world — to the audience's tactile experience and provide an immediate aesthetic experience. Like colored light, the optical apparatus transforms the appearance of colors by variations of depth-of-field or deep focus, by lens diffusion or reduced optical resolution. The cinematic representation alters the materials depicted and projects them onto the twodimensional surface of the film's skin. Surfaces are thus double-coded by their own materiality and the materiality of the optical support.

In his observations about functions of style in 1950s melodramas, Elsaesser quotes Douglas Sirk on his use of surface and depth-of-field: "Almost throughout the picture I used deep-focus lenses which have the effect of giving a harshness to the objects and a kind of enameled, hard surface to the colors, I wanted this to bring out the inner violence, the energy of the characters which is all inside them and can't break through" (Sirk, quoted in Elsaesser 1972, 43). Elsaesser goes on to explain: "It would be difficult to think of a better way of describing what this particular movie and indeed most of the best melodramas of the $50 \mathrm{~s}$ and early $60 \mathrm{~s}$ are about. Or for that matter, how closely, in this film, style and technique is related to theme" (Elsaesser 1972, 43). Accordingly, material surfaces and depth-of-field are an important part in strategies for films to address the viewers tactile perception by expressing subjectivity—in a way counter-intuitively — through textures. Remember the shimmering silk with jacquard patterns that is at the center of an oppressed eroticism in Wong Kar-wai's Fa yeung nin wa (2000), or the 
diffuse light and shallow depth-of-field in his My Blueberry Nights (2007), evoking a melancholic tone in tune with the female lead's inner state (see figure 8.1).

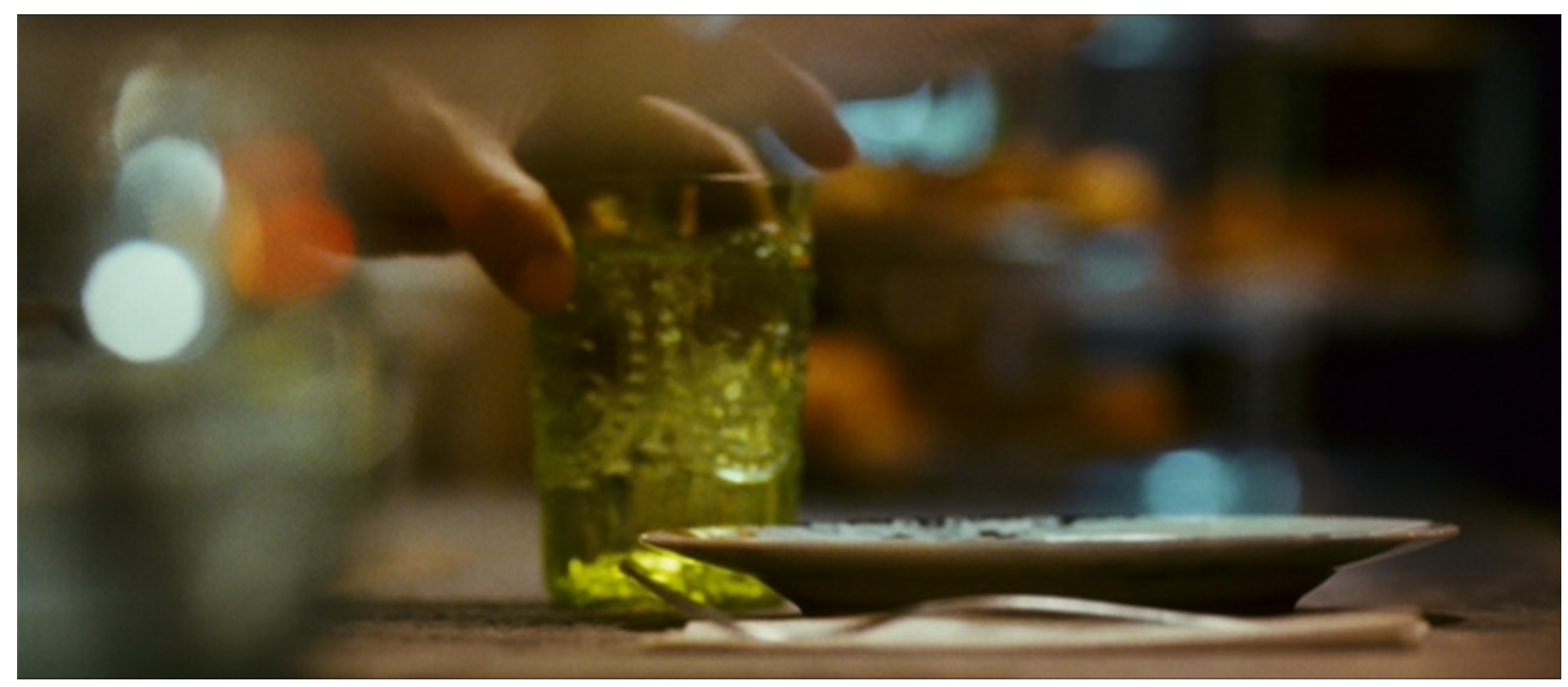

Figure 8.1: Shallow depth-of-field and materiality of an ornamented drinking glass in $M y$ Blueberry Nights.

In Douglas Sirk's All That Heaven Allows, we experience an interesting contrast between the hypocritical middle-class stratum suffocating the widow's awakening desires and the down-toearth world of her love interest, the gardener. Tactile properties of the surfaces, all represented in deep-focus cinematography, convey the corresponding feeling, shiny hard and polished metal and glass objects in the widow's beige and cream colored home versus natural and cosy coarse textures of wood and bricks in desaturated earth tones. While both color spectra are similar, the contrast is implemented by textures, variations in small-scale patterns, and their tactile dimensions. 
Recent films apply this approach to convey subjectivity through tactile features much more boldly. As Barker points out, horror films make extensive use of haptic dimensions, especially in addressing disgust, which always has a haptic dimension. Barker quotes Walter Benjamin's dictum that "all disgust is originally disgust at touching" $(2009,47)$. In evoking motor mimicry — the intuitive bodily reenactment of characters' moves or actions - films can arouse strong direct affects. "Vis-a-vis a disgusting filmic object—sometimes also a character in the act of being disgusted - we are overcome by an emotion that suddenly takes possession of our body, causing physical loathing or shuddering and forcing us to look away, gag, or even vomit" (Hanich 2009, 293-294).

Surface properties are instrumental in this domain. Blood, vomit, decaying corpses, and feces have specific states of viscosity, often somewhere between liquid and solid, semi-fluid organic matters with distinctive surface properties. Shiny, slimy objects - such as the grossly exaggerated green puke in The Exorcist (William Friedkin, 1973) or the huge blood puddles in Suspiria (Dario Argento, 1977) that shine in intensely saturated reds - arouse shivering responses or — depending on the viewers' attitude and the films' overall tonality-ironic alienation, even both at the same time.

Takashi Miike's Ôdishon (1999) is one of the recent horror films commonly cited for transgressing the traditional altar function of film by strongly addressing direct affects. Ôdishon connects bodily dimensions of the characters' violent experiences to a bold application of mood lighting and strong, often unusual colors. The sadistic femme fatale, for instance, is presented in white dresses, thus contradicting the conventional association of white with innocence. Only in a very few moments are these white dresses combined with other colors, in particular a red furry coat and - most importantly_-black leather accessories in the final torture scene. Again, as in 
Leave Her to Heaven, mixed lighting foreshadows catastrophe, here when the couple has their first sexual encounter. In the flashbacks we find an evenly ambiguous use of colors, when the heroine's ballet teacher approaches her to sexually abuse her with scorching hot sticks in a romantically lit room bathed in diffuse white light. In the most disturbing scenes, when a disfigured human creature is forced to swallow the heroine's semi-liquid creamy vomit, or during the seemingly endless torture scene with wires and needles in glistening metal, the almost unbearable disgust engulfs viewers in strong haptic reactions, enhanced by acoustic traits of the material properties of flesh and vomit. Towards the end of the film, in the torture scene, the subjective underscoring becomes obvious by flashbacks in monochrome mood lighting in blue that depict memories of sexual abuse by the ballet teacher as well as in the first sexual encounter with the male object of the heroine's revenge.

Likewise, Amer (Hélène Cattet and Bruno Forzani, 2009) combines a heightened sense of touch with mood lighting, interestingly again by attaching the perception in part to the child's perspective. Skin, water, sweat, pebbles, wood, fabrics, and hair are uncannily magnified and distorted by extreme close-ups, colored lights in unusual contrasts, shallow depth-of-field, fuzzy images, and motion blur to depict a mysterious universe by suppressing consistent information. The continuous withdrawal of orientation shifts the viewers' mode of reception from cognitively accessible narration into an associative mode, and closes the gap by providing a wealth of sensory details, both in the optical and acoustic representation. These details keep the spectator in a tense mode of curiosity, working to combine the fragments into a unified experience. Again, this experience is located in the realm of Stimmung between mood and ambiance. Touch in Amer is at the same time sexually laden—in part explicit, in part allusively—and frightening with an element of disgust. Due to the saturated colored lights, we never know whether the liquids 
entering the girl's room are water or blood or excrement of the dying and decaying person in an adjacent room. In a sex scene depicting the parents — observed by the child and therefore recalling the Freudian Urszene - this ambiguity between sex and horror, disgust or even death is played to its limits.

As Kirsten Moana Thompson (2015) rightly observes in her analysis of Tom Ford's $A$ Single Man (2009), digital color grading allows for much subtler changes of hues and colors. She centers her analysis of the film's use of colors around three "modalities in the history of film" (63): digital tools and stability of analog film colors, period color design at the threshold between Technicolor and chromogenic Eastmancolor in the 1950s and 1960s, and "pop art-inflected attention to chromatic surface" (64). With regard to surface, Thompson contradicts critical reception of chromophilia in Ford's debut as a filmmaker as "too pretty," "too decorative, too sensorially pleasurable to be high art, and yet too composed and 'arty' to be efficient entertainment" (75) by pointing out how self-reflexively the film's surface connects the three modes of color aesthetics.

With regard to the topic examined in this chapter, one must add the highly elaborate connection of the film's skin - the film's surface in the sense discussed by Thompson-and the subjectively infused surface colors in the diegesis and their visual representation on the screen. The grieving male protagonist's modernist house designed by John Lautner is a masculinely textured wood and glass construction that sets the tone for the restrictive palette in earth tones, brown, and beige hues. A cold/warm contrast in the scene of the protagonist's lover's death adds cool metal blue with a tinge of blood red. Only gradually is this restricted color scheme dissolved by animated secondary spot color correction, highlighting material properties of fabrics in women's dresses - but even more so in memories of his lover, part in black-and-white with stark 
contrasts that enhance the skin and water in front of the rock formations, progressively in more saturated red and green. In his slowly re-awakening erotic desire, the shift to saturated colors is underpinned by close-ups of skin, plants, flowers, lips. When he encounters an appealing love interest on a parking lot drenched in yellow sunlight reminiscent of commercials, the camera follows his intense gaze on the other man's body through intensifying close-ups, framing ever closer parts of his face, until the lips start to bloom in saturated red. Later he starts dating one of his students. The boy is wearing a pullover in seductively fluffy cream-colored angora. Similar to the over-the-top-stylized environment in which the meeting with the first love interest took place, the fluffiness of the wool is emphasized by the shallow depth-of-field that adds to the palpable softness of the fabric (see figure 8.2).

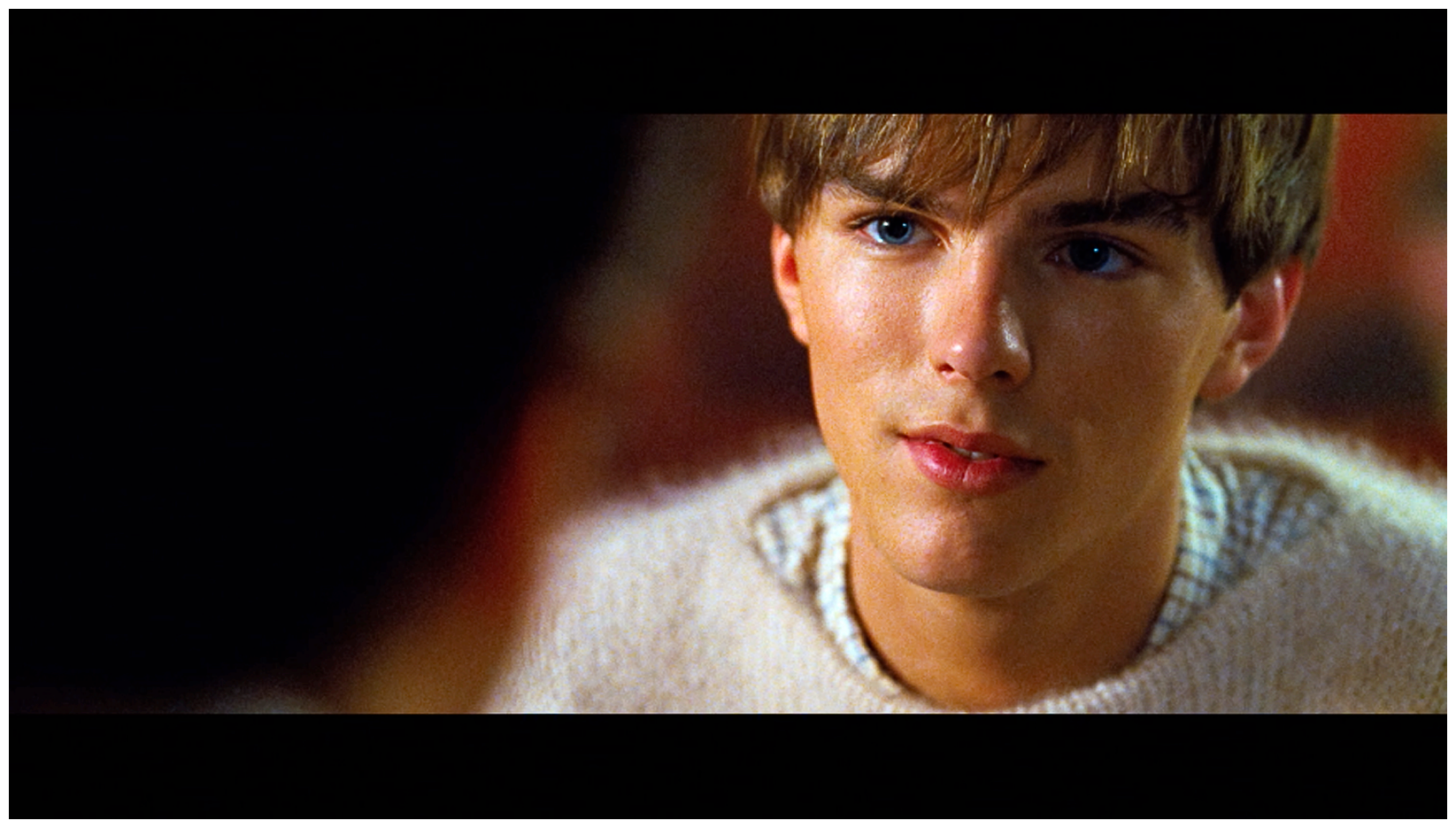

Figure 8.2: Shallow depth-of-field emphasizing the softness of Kenny's pullover in A Single Man. 
In summary, colors in film are an often overlooked aspect in expressing subjectivity. As discussed in this chapter, this function is not confined to narrative means of associating perceptions to inner states of characters, as described by Genette's concept of focalization (1972; 1983). Increasingly, aesthetic features of colors and their arrangement within a film's style are powerful instruments for connecting characters' moods and affective states to the audience's bodily reception by directly addressing their sensory and affective responses.

\section{References}

Albers, Josef. 1970. Interaction of Color: Grundlegung einer Didaktik des Sehens. Köln: Du Mont Schauberg.

von Arburg, Hans-Georg. 2010. “Ein sonderbares Gespinst von Raum und Zeit: Zur theoretischen Konstitution und Funktion von 'Stimmung' um 1900 bei Alois Riegl und Hugo von Hofmannsthal.” In Stimmung: Ästhetische Kategorie und künstlerische Praxis, edited by Kerstin Thomas, 13-30. Berlin: Deutscher Kunstverlag.

Bahrick, Lorraine E. and George Hollich. 2006. "Intermodal Perception." http://infantlab.fiu.edu/articles/Bahrick_Hollich_2006_Encyclopedia\%20revised_Intermo dal\%20Perception.pdf (last accessed January 15, 2016).

Barker, Jennifer M. 2009. The Tactile Eye: Touch and the Cinematic Experience. Berkeley: University of California Press.

Batchelor, David. 2006. "Chromophobia.” In Color: The Film Reader, edited by Angela Dalle Vacche and Brian Price, 63-75. New York: Routledge.

Bazin, André. 1975. Qu'est-ce que le cinéma? 9-17. Paris: Éditions du Cerf. 
Bordwell, David, Janet Staiger, and Kristin Thompson. 1985. The Classical Hollywood Cinema: Film Style and Mode of Production to 1960. New York: Columbia University Press.

Brinckmann, Christine N. 2014. Color and Empathy: Essays on Two Aspects of Film. Amsterdam: Amsterdam University Press.

Doyle, Christopher. 2003. “A Fantastic Fable.” American Cinematographer 84 (9): n.pag. http://www.theasc.com/magazine/sept03/cover/index.html (last accessed January 15, 2016).

Dyer, Richard. 2002. Only Entertainment. $2^{\text {nd }}$ edition. London: Routledge.

Elsaesser, Thomas. 1972. "Tales of Sound and Fury: Observations on the Family Melodrama." Monogram 4: 2-15.

Fell, John. 2000. "Rudolf Arnheim in Discussion with Film Students and Faculty, San Francisco State College, 7 May 1965.” Film History 12 (1): 11-16.

Flueckiger, Barbara. 2001. Sound Design: Die virtuelle Klangwelt des Films. Marburg: Schüren. Genette, Gérard. 1972. Figures III. Paris: Éditions du seuil.

Genette, Gérard. 1983. Nouveau discours du récit. Paris: Éditions du seuil.

Gage, John. 1993. Color and Culture: Practice and Meaning from Antiquity to Abstraction. London: Thames and Hudson.

Hanich, Julian. 2009. "Dis/Liking Disgust: The Revulsion Experience at the Movies.” New Review of Film and Television Studies 7 (3): 293-309.

Hanssen, Eirik Frisfold. 2006. Early Discourses on Colour and Cinema: Origins, Functions, Meanings. Stockholm: Almqvist \& Wiksell International. 
Meder, Thomas. 1994. "Michelangelo Antonionis Il Deserto rosso und seine Überlegungen zur Farbe.” In Natur und ihre filmische Auflösung, edited by Jan Berg and Kay Hoffmann, 71-77. Marburg: Timbuktu-Verlag.

Heller, Eva. 2004. Wie Farben wirken: Farbpsychologie, Farbsymbolik, kreative Farbgestaltung. Reinbek: Rowohlt.

Hering, Bertolt. 2007. "Runges Grün statt Fuji-Grün! Pamphlet wider die inkorrekte Objektivierung von Subjektivität.” Kultur \& Gespenster 4: 204-211.

Higgins, Scott 2007. Harnessing the Technicolor Rainbow: Color Design in the 1930s. Austin: University of Texas Press.

Hurlbert, Anya. 2013. “The Perceptual Quality of Color.” In Handbook of Experimental Phenomenology: Visual Perception of Shape, Space and Appearance, edited by Liliana Albertazzi, 369-394. Chichester: Wiley-Blackwell.

Kalmus, Natalie M. 1935. “Color Consciousness.” Journal of the Society of Motion Picture Engineers 25 (2): 139-147.

Kappelhoff, Hermann. 2004. Matrix der Gefühle: Das Kino, das Melodrama und das Theater der Empfindsamkeit. Berlin: Vorwerk 8.

Katz, David. 1935. The World of Colour. London: Kegan Paul.

Keating, Patrick. 2010. Hollywood Lighting from the Silent Era to Film Noir. New York: Columbia University Press.

Layton, James, Paolo Cherchi Usai, David Pierce, and Catherine A. Surowiec. 2015. The Dawn of Technicolor, 1915-1935. Rochester: George Eastman House.

Münsterberg, Hugo. 1916. The Photoplay: A Psychological Study. New York: Appleton. 
Neupert, Richard. 1990. “Technicolor and Hollywood: Exercising Color Restraint.” Post Script 10 (1): 21-29.

Newton, Isaac. 1704. Opticks: Or, a Treatise of the Reflexions, Refractions, Inflexions and Colours of Light. London: Samuel Smith and Benjamin Walford.

Peirce, Charles Sanders. 1932. The Collected Papers Vol. I: Principles of Philosophy. Cambridge, MA: Harvard University Press.

Plantinga, Carl. 2009. Moving Viewers: American Film and the Spectator's Experience. Berkeley: University of California Press.

Riley, Charles A. 1995. Color Codes: Modern Theories of Color in Philosophy, Painting and Architecture, Literature, Music, and Psychology. Hanover: University Press of New England.

Runge, Philipp Otto. 1810. Farben-Kugel, oder Construction des Verhaeltnisses aller Mischungen der Farben zueinander, und ihrer vollständigen Affinität. Hamburg: Perthes. Runge, Philipp Otto. 1840. Hinterlassene Schriften, 2 Bde. Hamburg: Perthes.

Sobchack, Vivian. 1992. The Address of the Eye: A Phenomenology of Film Experience. Princeton: Princeton University Press.

Street, Sarah. 2009. “'Colour Consciousness': Natalie Kalmus and Technicolor in Britain.” Screen 50 (2): 191-215.

Thompson, Kirsten Moana. 2015. "Falling in (to) Color: Chromophilia and Tom Ford's $A$ Single Man." The Moving Image 15 (1): 62-84.

Tye, Michael. 2015. “Qualia.” In The Stanford Encyclopedia of Philosophy, edited by Edward N. Zalta, n.pag. Stanford: Stanford University. 
http://plato.stanford.edu/archives/fall2015/entries/qualia/ (last accessed January 15, 2016).

Wach, Margarete. 2007. "Eine Insel der Freiheit? Slawomir Idziak im Gespräch mit der Filmwissenschaftlerin Margarete Wach über die Filmschule von Lodz.” In Ein Architekt der Sinnlichkeit: Die Farbenwelten des Kameramanns Slawomir Idziak, edited by Andreas Kirchner, Michael Neubauer, Karl Prümm, and Peter Riedel, 30-42. Marburg: Schüren.

Watkins, Liz. 2013. “Disharmonious Designs: Colour Contrast and Curiosity in Jane Campion's 'In the Cut.'” Necsus 2 (1): n.pag. http://www.necsus-ejms.org/disharmonious-designscolour-contrast-and-curiosity-in-jane-campions-in-the-cut/\#_edn10 (last accessed January $15,2016)$.

Wulff, Hans J. 2006. “Attribution, Konsistenz, Charakter: Probleme der Wahrnehmung abgebildeter Personen.” Montage/av 15 (2): 45-62.

Yumibe, Joshua. 2012. Moving Colors: Early Film, Mass Culture, Modernism. New Brunswick: Rutgers University Press.

\footnotetext{
${ }^{1}$ For an overview of the countless color processes invented in the course of film history, see “Timeline of Historical Film Colors": http://zauberklang.ch/filmcolors/ (last accessed January 15, 2016).

${ }^{2}$ Tinting and toning are the application of colors that submerged entire scenes in monochromatic or bi-chromatic hues.

${ }^{3}$ For a discussion of the concept of qualia, see, e.g., Tye 2015.
} 
${ }^{4}$ Such a systematic study of color aesthetics in large groups of films are the topic of this author's current research project FilmColors, funded by the European Research Council 2015-2020.

${ }^{5}$ For a detailed visual comparison of two dye-transfer prints of La Cucaracha, see http://zauberklang.ch/filmcolors/timeline-entry/1301/\#La_Cucaracha_\%281934\%29 (last accessed January 15, 2016).

${ }^{6}$ For a detailed visual comparison of two dye-transfer prints of All That Heaven Allows and Written on the Wind, see http://zauberklang.ch/filmcolors/timeline-entry/1445/ (last accessed January 15,2016$)$.

${ }^{7}$ There are different systems to organize colors in primary and secondary hues. The perceptually uniform CIE LAB system is based on four primaries as opposed to the three additive primaries red, green, and blue or the subtractive primaries cyan, yellow, and magenta. ${ }^{8}$ The term focalization was introduced by Gérard Genette $(1972 ; 1983)$ to describe the perceptual focus of a narration. In multiple focalization, several focalizers narrate one event from their different perspectives, for instance famously in Rashômon (Akira Kurosawa, 1950). 